\title{
Nanomole Bone Collagen Equivalents per Nanomole
}

National Cancer Institute

\section{Source}

National Cancer Institute. Nanomole Bone Collagen Equivalents per Nanomole. NCI

Thesaurus. Code C122217.

A unit of relative amount of substance concentration equal to nanomoles of bone

collagen equivalent weight per unit of substance concentration equal to one nanomole. 